\title{
E-wallet: factors influencing user acceptance towards cashless society in Malaysia among public universities
}

\author{
Norulhuda Abdullah ${ }^{1}$, Fauziah Redzuan ${ }^{2}$, Nor Aziah Daud ${ }^{3}$ \\ ${ }^{1}$ Universiti Kebangsaan Malaysia (UKM), Malaysia \\ ${ }^{2,3}$ Faculty of Computer and Mathematical Sciences, Universiti Teknologi MARA (UiTM), Malaysia
}

\begin{tabular}{l}
\hline Article Info \\
\hline Article history: \\
Received Jan 4, 2020 \\
Revised Mar 25, 2020 \\
Accepted Apr 9, 2020 \\
\hline
\end{tabular}

\section{Keywords:}

Cashless society

E-wallet

\begin{abstract}
The evolution of financial technology into digital payment has led to a new era of cashless society. In line with the global trend, the Malaysian Government has been committed to strengthen the agenda of a cashless society by actively promoting the use of e-Wallet through the establishment of the Interoperable Credit Transfer Framework (ICTF) policy in 2018. Although e-Wallet has been implemented since 2016, several previous studies have found that the level of acceptance is still relatively low while the main factors that influence the acceptance of e-Wallet in Malaysia still remain unclear. This study aims to identify the factors that influence the acceptance of e-Wallet towards establishing cashless society in Malaysia. Online survey using closed-ended questionnaires have been conducted among 400 respondents from students and employees of Malaysian public universities in Klang Valley. Collected data have been analyzed using descriptive statistics and inferential statistics which consist of Factor Analysis, Pearson Correlation and Multiple Linear Regression in Statistical Package for the Social Sciences (SPSS). Based on the findings, four factors are found to significantly influence e-wallet acceptance, which consist of Performance Expectancy (PE), Social Influence (SI), Facilitating Conditions (FC) and Trust (T). Facilitating Conditions (FC) is the most influential significant factor behind the acceptance of e-wallet among Malaysians.
\end{abstract}

Copyright $(2020$ Institute of Advanced Engineering and Science. All rights reserved.

\section{Corresponding Author:}

Fauziah Redzuan,

Faculty of Computer and Mathematical Sciences,

Universiti Teknologi MARA (UiTM),

40200 Shah Alam, Selangor, Malaysia.

Email: fauziahr@tmsk.uitm.edu.my

\section{INTRODUCTION}

The rapidly evolving technology around the world has transformed the landscape of industry including the financial sector. The evolution of financial technology into digital and electronic payment (e-payment) has led to a new era of cashless society, where the use of cash in financial transactions is becoming less popular. Cashless society has been the sole goal of all countries around the world, and research on the implementation of cashless transactions have been widely carried out [1-3]. Cashless society refers to a society in which electronic money consisting of online payments, direct debits, credit and debit cards, are used to pay all bills and debits [4]. The transformation from the traditional payment method by using physical currency to electronic payment is the world's leading agenda for cost savings purposes in order to provide a safe, convenient and the best service to customers [2, 4].

In line with the global trend of financial technology evolution in e-payments towards cashless society, Bank Negara Malaysia (BNM) has taken the initiative to introduce the Financial Sector Blueprint (FSBP) 2011-2020, as the driver of the e-payment agenda to build a cashless society in Malaysia by the year 2020. On July 21, 2016, Maybank Group President has launched MaybankPay as the first e-Wallet payment method through mobile phone or the mobile 
wallet, in conjunction with Maybank Treats Fair 2016 in Kuala Lumpur. MaybankPay has revolutionized Malaysia's e-payment, as it offers a new gateway where cardholders can "carry their card within their mobile devices". It has been the starting point of the transformation for customers to make cashless payments through smartphones [5].

Since the early stages of its implementation, Malaysia has taken its time to adopt this technology, and e-Wallet has become a popular topic of discussion in 2017 when the former Prime Minister of Malaysia and the Founder and Executive Chairman of Alibaba Group launched the Digital Free Trade Zone (DTFZ) [6]. All parties are moving forward to participate in this transformation, especially among the providers and merchants, by imitating Alipay as a new business model. E-Wallet has become a phenomenon in digital and electronic commerce in Malaysia, following the implementation of the Interoperable Credit Transfer Framework (ICTF) on 1st July 2018. The ICTF is one of BNM's initiatives to embrace the use of e-Wallet in Malaysia through a unified network, by providing an infrastructure for shared payment between bank e-Wallet and non-bank e-Wallet [7]. After that date, the e-Wallet growing competition became more vibrant with the introduction of various e-Wallet applications by merchants in providing services to consumers. Among the e-Wallet applications include Boost, FavePay, Touch 'n Go e-Wallet, GrabPay, BigPay, and Razer Pay.

E-Wallet is the acronym for electronic wallet, and in some cases, is also termed as digital wallet. It refers to a payment system technology that transforms the physical wallet features into a digital environment, by allowing users to perform their electronic transactions using numerous type of payment methods including debit cards, credit cards, loyalty cards and bank accounts [8-13]. The integration between the e-Wallet system and several bank accounts, or debit and credit cards, does not only provide convenience to users, but also enhances security, speed, ease of use and is time-saving $[8,10,14,15]$. Users can make their payment without swiping off their debit and credit cards which is attributed to the seamless mobility features in e-Wallet [15].

Most previous studies highlighted that e-Wallet comes with many advantages or benefits, such as usefulness [10, 16, 17], convenience [10, 17], promotions and security [17]. According to [18], usefulness, convenience and brand loyalty are also the major factors that play a significant role in customers' acceptance of e-Wallet. Even though the e-Wallet comes with many benefits, there are still some issues or challenges in its implementation. Among the main issues or challenges are security and confidentiality, which are from multiple aspects such as security and safety of bank account or fund [18], and security of information if the phone is lost or stolen [9]. As a new technology in the payment industry, the e-Wallet brings new risks in cyber security. Users are exposed to risks while performing their online transactions. Among the risks are hacking, malware and phishing attacks [17]. According to [19], although e-Wallet technology has been implemented for over two years in Korea with 100,000 readers and terminals at merchant's Point of Sale (POS) and multiple of e-Wallet software, there is a key problem when customers have little interest in using this technology. In Mumbai on the other hand, the internet connection has been a major obstacle for users to adopt e-Wallet, as e-Wallet requires internet access to function [18]. The availability of e-Wallet is dependent on active internet connection and devices such as tablets or mobile phones. Users will not gain an access to E-Wallet if the phone runs out of battery or does not have an internet coverage [17].

Through many previous studies [8-14, 16, 19-21] it was found that researches on e-Wallet have been widely conducted globally. There are a number of factors considered by e-Wallet users in making the decision to choose e-Wallet as a payment method in their electronic transactions. [21] studied on e-Wallet acceptance by investigating the factors that influence Gen Y in India by using five constructs adapted from the Technology Acceptance Model (TAM). While [16] on the other hand, concluded that controllability and security, the need for performance enhancement, societal influence and usefulness as the factors in explaining Punjab's motivation in using e-Wallet. Societal influence and usefulness factors are found to influence people towards the usage of digital wallet with discounts, convenience and cashback. [20] have concluded that their research has been conducted to only analyse a few factors of e-Wallet adaptation, and recommended for other research to add more factors in future research models. Even though usefulness has been named in many studies as one of significant factors in e-Wallet usage, that study indicated that it has no impact on e-Wallet adoption. Perceived security was found to be the biggest factor, followed by technical information.

Although e-Wallet has been implemented for several years in Malaysia, it was found that e-Wallet adoption is still in its infancy [17, 22]. The level of acceptance of e-Wallet technology in Malaysia is still relatively low, given the fact that it has been introduced for a number of years to Malaysians. Most Malaysians have very limited knowledge and do not realize how convenient e-Wallet is. According to the Malaysia's Payment Landscape 2018 Report, the use of non-cash payment methods favoured by the majority of Malaysians are debit cards and online banking, while only few use mobile wallets (8\%) [23]. Besides that, the main factors that influence the acceptance of e-Wallet in Malaysia also remains unclear. Through a study, it was found that security issue is a major drawback in the use of e-Wallet application [23, 24]. Among the security concerns identified in the Nielsen Payment Landscape Report in 2018 include card fraud, missing transactions, fake websites and the risk of losing mobile phones. There are many factors that influence users' acceptance of e-Wallet. Therefore, it is necessary for a study to be carried out to identify the factors that influence users to accept e-Wallet in Malaysia.

Indonesian J Elec Eng \& Comp Sci, Vol. 20, No. 1, October 2020 : 67 - 74 


\section{RESEARCH METHOD}

The aim of this study is to identify the factors that influence the acceptance of e-Wallet towards a cashless society in Malaysia among public universities. This study uses a quantitative approach and it was conducted through an online survey using the google form questionnaire on the targeted focus group, comprising students and employees of Malaysian public universities in Klang Valley. Six Malaysian public universities in Klang Valley consisting of Universiti Malaya (UM), Universiti Kebangsaan Malaysia (UKM), Universiti Putra Malaysia (UPM), Universiti Teknologi MARA (UiTM), Universiti Islam Antarabangsa Malaysia (UIAM) and Universiti Pertahanan Nasional Malaysia (UPNM). The main reason for this study being conducted in public universities is because cashless payment is one of the goals that the universities want to achieve [25, 26]. Four main phases have been involved in this research consisting of Planning and Literature Review phase, Design phase, Data Collection and Analysis phase as well as Documentation phase. In the design phase, the research model, the research hypothesis and the research instrument have been determined.

\subsection{Research model and hypothesis}

This study uses the Unified Theory of Acceptance and Use of Technology (UTAUT) model. This selection is due to the fact that the model has gone through empirical test, where it is proven to be comprehensive and it is relatively better compared to other models [27, 28]. UTAUT is also seen as the best practice model for measuring consumer acceptance which is more appropriate for users than for organizations. Thus, it is more suitable to understand studies that are mostly affected by human factors [29]. UTAUT model is adapted from [27, 30-36] as guidelines in identifying key factors that influence the acceptance of e-wallet towards a cashless society in Malaysia. The proposed research model consists of seven (7) constructs; Performance Expectancy (PE), Effort Expectancy (EE), Facilitating Condition (FC), Social Influence (SI), Security (S), Trust (T) and Behavioral Intention (BI) as shown in Figure 1.

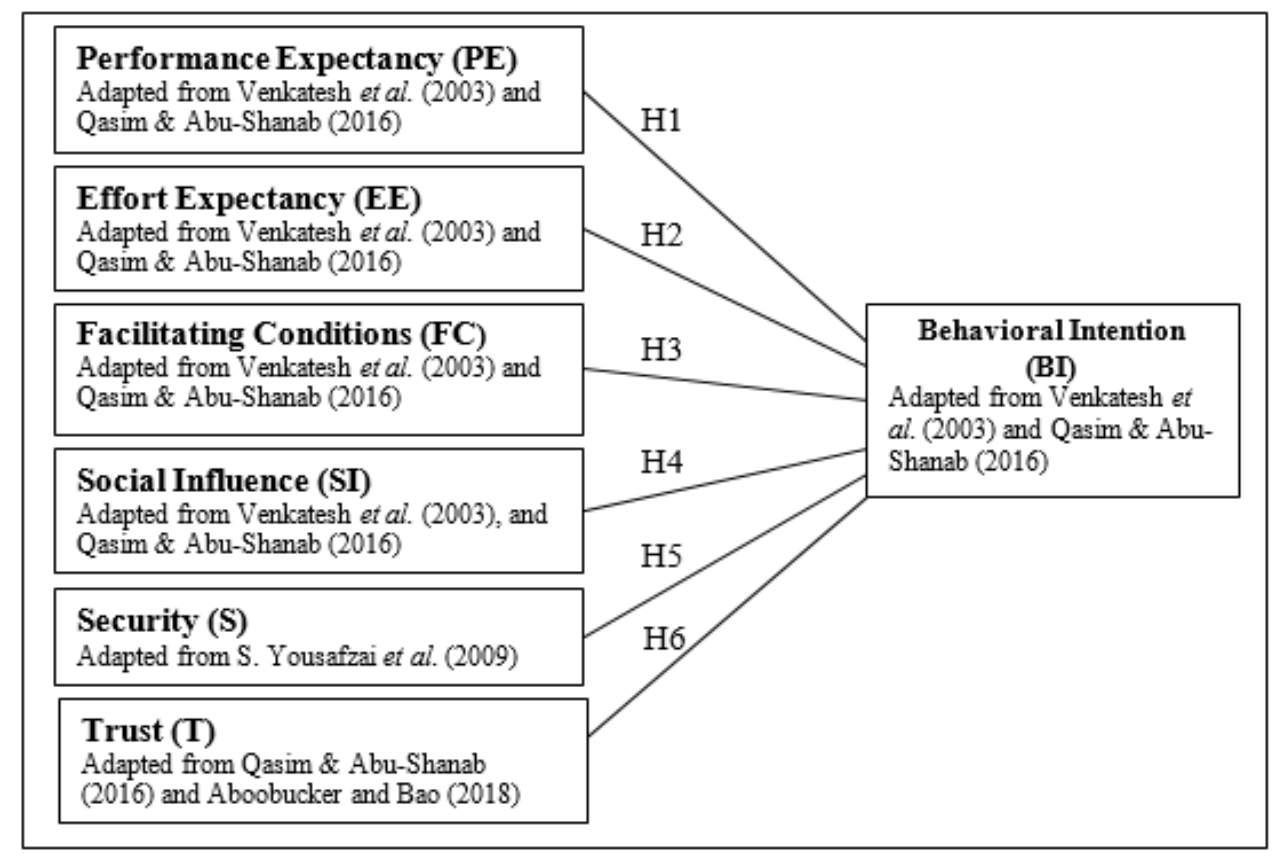

Figure 1. Research model

The hypothesis is an assumption made in the study and may differ from actual results after data collection and analysis. They are:

H1: Performance expectancy (PE) has a significant influence on the Behavioral Intention (BI) to use e-Wallet.

H2: Effort Expectancy (EE) has a significant influence on the Behavioral Intention (BI) to use e-Wallet.

H3: Social Influence (SI) has a significant influence on the Behavioral Intention (BI) to use e-Wallet.

H4: Facilitating Conditions (FC) has a significant influence on the Behavioral Intention (BI) to use e-Wallet.

H5: Security (S) has a significant influence on the Behavioral Intention (BI) to use e-Wallet.

H6: Trust (T) has a significant influence on the Behavioral Intention (BI) to use e-Wallet. 


\subsection{Research instrument}

The research instrument used in this study is a closed-ended questionnaire. The questionnaire has two segments consisting of sections A and section B. Section A is information related to respondents' demographics while section $\mathrm{B}$ is information related to the question of measuring e-Wallet acceptance. The Likert scale from 1 (Disagree) to 5 (Strongly Agree) is used as a measurement in this study.

\section{RESULTS AND ANALYSIS}

The total respondents are 400 consisting of 200 students and 200 employees. The quantitative data from the questionnaires were collected and analysed using Statistical Packages for Social Science (SPSS) to get results. Collected data have been analyzed using descriptive statistics and inferential statistics. The three techniques in inferential statistics consisting of Factor Analysis, Pearson Correlation and Multiple Linear Regression (MLR) were used in this study.

\subsection{Descriptive statistics}

Table 1 shows the total of respondents by the Categories of universities.

Table 1. Summary of respondents

\begin{tabular}{ccc}
\hline University & Frequency & Percent \\
\hline UM & 53 & 13.3 \\
UKM & 115 & 28.7 \\
UPM & 58 & 14.5 \\
UiTM & 109 & 27.3 \\
UIAM & 57 & 14.2 \\
UPNM & 8 & 2.0 \\
Total & 400 & 100.0 \\
\hline
\end{tabular}

\subsection{Factor analysis}

This study uses the Principle Component Factor Analysis (PCA) with Varimax-Kaiser Normalization Rotation Method. Factor Loading for all variables (PE, EE, SI, FC, S, T) above 0.3. According to [37], correlation above 0.3 for all variables implies that the factors are related and Variamax Rotation method is warranted. Test index of The Kaiser-Meyer-Olkin $=.944$ and sig. value $<0.05$ as shown in Table 2 indicates that the data were considered appropriate to factor analysis.

Table 2. Summary of factor analysis

\begin{tabular}{ll}
\hline \multicolumn{2}{c}{ KMO and Bartlett's Test } \\
\hline Kaiser-Meyer-Olkin Measure of Sampling Adequacy & .944 \\
Bartlett's Test of Sphericity (sig.) & .000 \\
\hline
\end{tabular}

\subsection{Pearson correlation}

The role of Pearson's Correlation is to determine the relationship in linear regression or linear relationship between two continuous variables [38] of e-Wallet acceptance which is Behavioral Intention to Use (BI) as dependent variable with each of independent variables consisting of Performance Expectancy (PE), Effort Expectancy (EE), Social Influence (SI), Facilitating Conditions (FC), Security (S) and Trust (T). The Correlation Coefficient value symbolized by $\mathrm{R}$ formulas return a value between -1 and 1 in measuring how strong relationship is between two variables where: 1 indicates a strong positive relationship, -1 indicates a strong negative relationship and 0 indicates no relationship at all. However, [39] classified a strong relationship with five indications of the R value consisting of Very Strong (0.80-1.0), Strong (0.60-0.79), Moderate (0.40-0.59), Weak (0.20-0.39) and Very Weak (0.00-0.19). The result of Pearson Correlation is shown numerically in Table 3. As a summary, the $\mathrm{R}$ value for all constructs (PE, $\mathrm{EE}, \mathrm{SI}, \mathrm{FC}, \mathrm{S}, \mathrm{T})$ is higher than 0.50 with the indicator of moderate and strong relationship.

Table 3. Pearson correlation result

\begin{tabular}{cccc}
\hline $\mathrm{N}=400$ & \multicolumn{3}{c}{ Construct (Dependent Variables: BI) } \\
Construct (Independent Variables) & Pearson Correlation (R) & Sig. (2-tailed) $(\rho)$ & Result \\
\hline PE & $.619^{* *}$ & 0.000 & Strong \\
EE & $.630^{* *}$ & 0.000 & Strong \\
SI & $.592^{* *}$ & 0.000 & Moderate \\
FC & $.691^{* *}$ & 0.000 & Strong \\
S & $.538^{* *}$ & 0.000 & Moderate \\
T & $.568^{* *}$ & 0.000 & Moderate \\
\hline **. Correlation is significant at the 0.01 level (2-tailed).
\end{tabular}




\subsection{Multiple linear regression (MLR)}

MLR is the ideal technique to be used if the set of independent variables are two or more variable associated with one continuous dependent variable [37, 38, 40]. Six constructs which consist of Performance Expectancy (PE), Effort Expectancy (EE), Social Influence (SI), Facilitating Conditions (FC), Security (S), and Trust (T) as independent variable were analysed concurrently to examine the effect on Behavioral Intention to Use (BI) as dependent variable.

As a result of MLR analysis in Table 4, the $\mathrm{R}$ value is 0.757 indicates a strong relationship as it closer to +1 . Besides that, in statistics, the coefficient of determination known as R Square (R2) in the analysis model describes the proportion of variation in dependent variable that is predictable from the independent variables. Based on the result as shown in Table 4, it is observed that the R2 value by MLR model is 0.573 , which means that $57 \%$ of the BI variation is from PE, EE, SI, FC, S and T, while the remaining $(43 \%)$ is from other factors that are not taken into consideration in this study.

Table 4. MLR summary result

\begin{tabular}{ccccccccc}
\hline $\mathrm{R}$ & $\begin{array}{c}\text { R Square } \\
(\mathrm{R} 2)\end{array}$ & $\begin{array}{c}\text { Adjusted R } \\
\text { Square }\end{array}$ & $\begin{array}{c}\text { Std. Error of the } \\
\text { Estimate }\end{array}$ & $\begin{array}{c}\text { R Square } \\
\text { Change }\end{array}$ & F Change & dfl & df2 & $\begin{array}{c}\text { Sig. F } \\
\text { Change }\end{array}$ \\
\hline $.757^{\mathrm{a}}$ & .573 & .566 & .51868 & .573 & 87.762 & 6 & 393 & $.000^{\mathrm{a}}$ \\
\hline
\end{tabular}

Besides that, Correlation Coefficient value for each independent variable (PE, EE, SI, FC, S and T) with the dependent variable (BI) are shown in Table 5. The Sig. value $<0.05$ in this analysis indicates a significant relationship. As a summary, PE, SI, FC and T have a significant relationship on the behavioral intention to use e-Wallet. The Beta and Sig. value can determine the highest influence for relationship between independent variable and dependent variables. Among Beta and Sig. value PE (.202, .000), EE (.095, .084), SI (.115, .015), FC (.323, .000), S (.025, .670) and $\mathrm{T}(0.145, .015), \mathrm{FC}$ is the highest significant influence factor for Behavioral Intention (BI). The tolerance values between 0.310 to 0.484 and the Variance Inflation Factor (VIF) value between 2.064 to 3.225 indicate that value is acceptable and that there is no multi collinearity as the tolerance scale is above 0.1 and the VIF is below 10 . According to [41], multi collinearity refers to a kind of data interruption.

Table 5. MLR Correlation Coefficient Result

\begin{tabular}{|c|c|c|c|c|c|c|c|}
\hline \multirow{3}{*}{ Model } & & & \multirow{3}{*}{$\begin{array}{c}\text { Coefficients }^{\mathrm{a}} \\
\text { Standardized Coefficients } \\
\text { Beta } \\
\end{array}$} & \multirow{3}{*}{$\mathrm{t}$} & \multirow{3}{*}{ Sig. } & \multirow{2}{*}{\multicolumn{2}{|c|}{ Collinearity Statistics }} \\
\hline & \multicolumn{2}{|c|}{$\begin{array}{l}\text { Unstandardized } \\
\text { Coefficients }\end{array}$} & & & & & \\
\hline & B & Std. Error & & & & Tolerance & VIF \\
\hline (Constant) & .164 & .171 & & .958 & .339 & & \\
\hline PE & .203 & .049 & .202 & 4.171 & .000 & .461 & 2.168 \\
\hline $\mathrm{EE}$ & .100 & .058 & .095 & 1.730 & .084 & .364 & 2.750 \\
\hline SI & .120 & .049 & .115 & 2.436 & .015 & .484 & 2.064 \\
\hline $\mathrm{FC}$ & .390 & .067 & .323 & 5.822 & .000 & .353 & 2.837 \\
\hline S & .025 & .058 & .025 & .427 & .670 & .315 & 3.173 \\
\hline $\mathrm{T}$ & .145 & .059 & .145 & 2.447 & .015 & .310 & 3.225 \\
\hline
\end{tabular}

The MLR method was carried out separately for two groups consisting of students and employees to examine the difference in behavioral intention to use e-Wallet. The result in Table 6 shows that there are differences between students and employees in behavioral intention to use e-Wallet. The differences are Performance Expectancy (PE), Social Influence (SI), Facilitating Conditions (FC) and Trust (T) which have a significant influence on the behavioral intention of using e-Wallet for students while Performance Expectancy (PE) and Facilitating Conditions (FC) have a significant influence on the behavioral intention of using e-Wallet for employees.

Table 6. MLR Correlation Coefficient Result by group

\begin{tabular}{|c|c|c|c|c|}
\hline \multicolumn{5}{|c|}{ Coefficients $^{\text {a }}$} \\
\hline Model & Student & & Employee & \\
\hline & Standardized Coefficients (Beta) & Sig. & Standardized Coefficients (Beta) & Sig. \\
\hline (Constant) & & .826 & & .290 \\
\hline $\mathrm{PE}$ & .171 & .012 & .206 & .006 \\
\hline $\mathrm{EE}$ & .127 & .088 & .052 & .534 \\
\hline SI & .143 & .030 & .127 & .079 \\
\hline $\mathrm{FC}$ & .347 & .000 & .274 & .001 \\
\hline$S$ & -.081 & .364 & .108 & .191 \\
\hline $\mathrm{T}$ & .191 & .029 & .150 & .079 \\
\hline
\end{tabular}


This study is successful in exploring the factors that influence the acceptance of e-Wallet towards a cashless society in Malaysia among public universities in Klang Valley. As a summary, there are four factors as shown in Figure 2 which significantly influence e-Wallet acceptance, consisting of Performance Expectancy (PE), Social Influence (SI), Facilitating Conditions (FC) and Trust (T), where Facilitating Conditions (FC) is the most influential significant factor behind the acceptance of e-Wallet among Malaysians. Effort Expectancy (EE) and Security (S) are not the significant factors that influence e-Wallet acceptance in this study. However, for the multi-group comparison between students and employees, Performance Expectancy (PE), Social Influence (SI), Facilitating Conditions (FC) and Trust (T) are factors that significantly influence the behavioral intention of using e-Wallet for students while Performance Expectancy (PE) and Facilitating Conditions (FC) are factors that significantly influence the behavioral intention of using e-Wallet for employees. FC is the most significant factor for students and employees. Table 7 shows the summary of hypotheses result in this study.

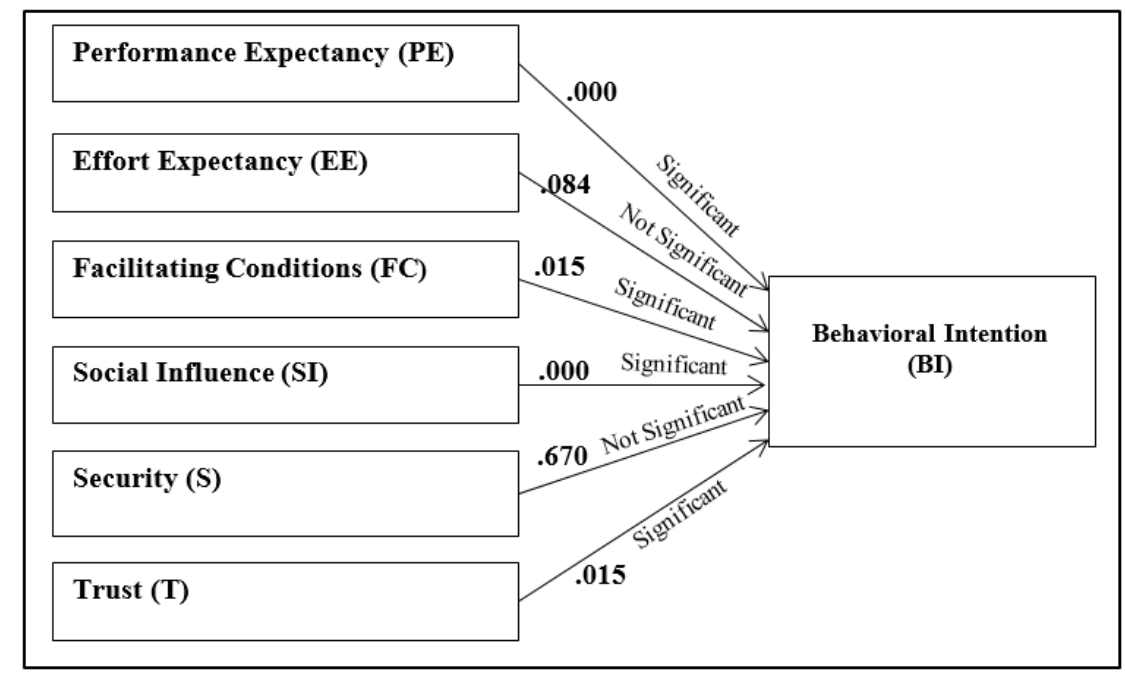

Figure 2. The Research model relationship between acceptance factors and behavioral intention (BI)

Table 7. Hypothesis result

\begin{tabular}{lccc}
\hline \multicolumn{1}{c}{ Hypothesis } & Sig. Value ( $\rho$ ) & \multicolumn{1}{c}{ Indicator } \\
\hline H1: Performance Expectancy (PE) has a significant influence on the Behavioral Intention & 0.000 & Significant \\
(BI) to use e-Wallet. & 0.084 & Not Significant \\
H2: Effort Expectancy (EE) has a significant influence on the Behavioral Intention (BI) to & & Significant \\
use e-Wallet. & 0.015 & 0.000 & Significant \\
H3: Social Influence (SI) has a significant influence on the Behavioral Intention (BI) to use & \\
e-Wallet. & & 0.670 & Not Significant \\
H4: Facilitating Conditions (FC) has a significant influence on the Behavioral Intention (BI) & Significant \\
to use e-Wallet. & & 0.015 &
\end{tabular}

\section{CONCLUSION}

In conclusion, this study is important to assess the extent to which e-Wallet technology is accepted in Malaysia, considering the fact that the government has taken various initiatives to ensure that this technology can be optimally utilized. Based on the findings, this study indicates that e-Wallet has successfully started to attract Malaysians in performing their electronic payment transaction after the implementation of Interoperable Credit Transfer Framework (ICTF) in Malaysia. The findings from this study can be a means for e-Wallet players to understand the factors that influence the acceptance of e-Wallet among their customers, which can be used to provide relatively better services as required by the customers, thereby indirectly increasing the customers' decision of using the e-Wallet when making purchases. Besides that, the findings from this study can also be the basis for public universities management to decide on the best e-Wallet provider in creating a strategic partnership for the implementation of e-Wallet applications in universities. 
There are still a lot of improvements or opportunities for further research to take place in the future. Future studies may consider e-Wallet acceptance factors other than Performance Expectancy (PE), Effort Expectancy (EE), Social Influence (SI), Facilitating Conditions (FC), Security (S), and Trust (T) because, based on data analysis findings, these factors only vary about $53 \%$ whereby there are still $47 \%$ of other factors that influence of e-Wallet acceptance. Facilitating Conditions (FC) is the most significant factor influencing the acceptance of e-Wallet among Malaysians. Therefore, future research on e-Wallet should be conducted not only on acceptance studies but also on technology infrastructure or facilities, features and function. The future work can focus more on current technology and security of e-Wallet.

\section{REFERENCES}

[1] M. Olusola, A. Oludele, O. Chibueze, and O. Samuel, "Cashless society: Drive's and challenges in Nigeria," Int. J. Inf. Sci. Tech., vol. 3, no. 2, pp. 1-11, 2013.

[2] H. H. Tee and H. B. Ong, "Cashless payment and economic growth," Financ. Innov., vol. 2, no. 1, pp. 1-9, 2016.

[3] H. Ha, B. Kadar, S. Syarmila, and B. Sameon, "Malaysia towards cashless society," Proc. 3rd Int. Symp. Inf. Internet Technol. (SYMINTECH 2018), vol. 565, pp. 34-42, 2019.

[4] O. S. Akinola, "Cashless society, problems and prospects, data mining research potentials," Int. J. Comput. Sci. Telecommun., vol. 3, no. 8, pp. 49-55, 2012.

[5] Maybank, "Maybank launches Malaysia's first mobile wallet payment convenience," Maybank, 2016. [Online]. Available: https://www.maybank.com/iwov-resources/corporate_new/document/my/en/pdf/corporate-newsrelease/2016/TreatsFair2016.pdf.

[6] "Malaysia launches world's first digital free trade zone," Malaysia Digital Economy Corporation, 2017. [Online]. Available: https://www.mdec.my/news/malaysia-launches-worlds-first-digital-free-trade-zone.

[7] L. Z. Wei and D. K. P. Tsu, "Transforming mobile phones into e-wallets in Malaysia," Bank Negara Malaysia Q. Bull., pp. 35-43, 2018.

[8] A. Upadhayaya, "Electronic commerce and e-wallet," Int. J. Recent Res. Rev., vol. 1, no. 1, pp. 37-41, 2012.

[9] B. Yahid, A. Shahbahrami, and M. B. Nobakht, "Providing security for e-wallet using e-cheque," 7th International Conference on e-Commerce in Developing Countries: with focus on e-Security, pp. 1-4, 2013.

[10] M. Salah Uddin and A. Yesmin Akhi, "E-wallet system for Bangladesh an electronic payment system," Int. J. Model. Optim., vol. 4, no. 3, pp. 216-219, 2014.

[11] P. Kalyani, "An Empirical study about the awareness of paperless e-currency transaction like e-wallet using ICT in the youth of India," J. Manag. Eng. Inf. Technol., vol. 3, no. 3, pp. 2394-8124, 2016.

[12] J. Sharma, "Importance of e-wallets in cashless economy (A post demonetisation study with special reference to Ahmedabad City)," Proc. Seventh Middle East Conf. Glob. Business, Econ., pp. 1-13, 2018.

[13] I. Shingari, "Future of e-wallets: A perspective from under graduates," Int. Journals Adv. Res. Comput. Sci. Softw. Eng., vol. 7, no. 8, pp. 146-150, 2018.

[14] A. Cole, S. Mcfaddin, C. Narayanaswami, A. Tiwari, and Y. Heights, "IBM research report toward a mobile digital wallet toward a mobile digital wallet," Building, vol. 24965, 2009.

[15] S. Singh and R. Rana, "Study of consumer perception of digital payment mode," J. Internet Bank. Commer., vol. 22, no. 3, pp. 1-14, 2017.

[16] K. Taheam, R. Sharma, and S. Goswami, "Drivers of digital wallet usage: Implications for leveraging digital marketing," Int. J. Econ. Res., vol. 13, no. 1, pp. 175-186, 2017.

[17] Y. Meiking, "Cashing in on e-wallets," 2019. [Online]. Available: https://www.thestar.com.my/news/nation/2019/02/03/cashing-in-on-ewallets-its-a-growing-trend-more-people-areusing-ewallets-in-their-phones-these-days

[18] R. HS, “Adoption of digital wallet by consumers," BVIMSR's J. Manag. Res., vol. 8, no. 1, 2016.

[19] D. H. Shin, "Towards an understanding of the consumer acceptance of mobile wallet," Comput. Human Behav., vol. 25, no. 6, pp. 1343-1354, 2009.

[20] S. Punwatkar and M. Verghese, "Adaptation of e-wallet payment: An empirical study on consumers' adoption behavior in Central India," International Journal of Advanced in Management, Technology and Engineering Sciences, vol. 8, no. 3, pp. 1147-1156, 2018.

[21] J. Trivedi, "Factors determining the acceptance of e-wallet," Int. J. Appl. Mark. Manag., vol. 1, no. 2, pp. 42-53, 2017.

[22] Y. C. Mei, "Factors influencing consumers' perceived usefulness usefulness of m-wallet in Klang Valley, Malaysia," Rev. Integr. Bus. Econ., vol. 8, no. 4, pp. 1-23, 2019.

[23] "Cash or cashless? Malaysia's shifting payment landscape," The Nielsen Company (US), 2019. [Online] Available: https://www.nielsen.com/apac/en/insights/article/2019/cash-or-cashless-malaysias-shifting-payment-landscape/

[24] T. J. Yee, "NIELSEN sees security concerns as main barrier to e-wallet adoption," 2019. [Online]. Available: https://www.digitalnewsasia.com/digital-economy/nielsen-sees-security-concerns-main-barrier-e-wallet-adoption

[25] Z. Mustafa, "UTM to turn into a cashless campus," New Straits Times, 2017. [Online] Available: https://www.thestar.com.my/tech/tech-news/2017/11/02/utm-is-set-to-become-a-cashless-campus

[26] NST Education, "Cashless in UUM with kiplePay," New Straits Times, 2019. [Online] Available: https://www.thestar.com.my/business/business-news/2019/05/06/uum-goes-cashless-with-kiplepay/

[27] Venkatesh, Morris, Davis, and Davis, "User acceptance of information technology: Toward a unified view," MIS $Q .$, vol. 27, no. 3, pp. 425-478, 2003. 
[28] S. Chakraborty and D. Mitra, "A study on consumers adoption intention for digital wallets in India," Int. J. Cust. Relations, vol. 6, no. 1, pp. 38-57, 2018.

[29] [A. Kiwanuka, "Acceptance process: The missing link between UTAUT and diffusion of innovation theory," Am. J. Inf. Syst., vol. 3, no. 2, pp. 40-44, 2015.

[30] H. Qasim and E. Abu-Shanab, "Drivers of mobile payment acceptance: The impact of network externalities," Inf. Syst. Front., vol. 18, no. 5, pp. 1021-1034, 2016.

[31] S. Alwahaishi and V. Snášel, "Modeling the determinants affecting consumers' acceptance and use of information and communications technology," Int. J. E-Adoption, vol. 5, no. 2, pp. 25-39, 2013.

[32] I. Aboobucker and Y. Bao, "What obstruct customer acceptance of internet banking? security and privacy, risk, trust and website usability and the role of moderators," J. High Technol. Manag. Res., vol. 29, no. 1, pp. 109-123, 2018.

[33] S. Y. Yousafzai, G. R. Foxall, and G. R. Foxall, "Explaining internet banking behavior: theory of reasoned action, theory of planned behavior, or technology acceptance model?," J. Appl. Soc. Psychol., vol. 40, no. 5, pp. 1172-1202, 2010.

[34] N. H. M. Ariffin et al, "Acceptance of mobile payments by retailers using UTAUT model," Indonesian Journal of Electrical Engineering and Computer Science, vol 19, no. 1, pp. 149-155, 2020.

[35] N. Ya'acob, et al, "A cashless payment transaction (CPaT) using RFID technology," Indonesian Journal of Electrical Engineering and Computer Science, vol 16, no. 1, pp. 191-199, 2019.

[36] Z. Mohammed and F. Redzuan, "Parent's acceptance on wearable technology for children's safety," Indonesian Journal of Electrical Engineering and Computer Science, vol 17, no. 2, pp. 1066-1073, 2020.

[37] P. E. Spector, "Method variance in organizational research: truth or urban legend?," Organ. Res. Methods, vol. 9, no. 2, pp. 221-232, 2006.

[38] J. Pallant, SPSS Survival Manual: A step by step guide to data analysis using SPSS for Windows (Version 12), 2005.

[39] J. D. Evans, Straightforward Statistics for the Behavioral Sciences, Brooks/Cole Publishing, Pacific Grove, 1996.

[40] M. H. A. Ong and Fadilah Puteh, "Quantitative data analysis: choosing between SPSS, PLS and AMOS in social science research," Int. Interdiscip. J. Sci. Res., vol. 3, no. 1, pp. 14-25, 2017.

[41] B. G. Tabachnick and L. S. Fidell, Using multivariate statistics, 5th ed. Boston, MA: Allyn \& Bacon Publication, 2007. 